\title{
A Model and Risk Score for Predicting Nevirapine-Associated Rash among HIV-infected Patients: In Settings of Low CD4 Cell Counts and Resource Limitation $^{\S}$
}

\author{
Sasisopin Kiertiburanakul ${ }^{*}, 1$, Somnuek Sungkanuparph ${ }^{1}$, Kumthorn Malathum ${ }^{1}$, \\ Siriorn Watcharananan ${ }^{1}$, Boonmee Sathapatayavongs ${ }^{1}$, Angkana Charoenyingwattana ${ }^{2}$, \\ Surakameth Mahasirimongkol ${ }^{3}$ and Wasun Chantratita ${ }^{4}$
}

\author{
${ }^{I}$ Department of Medicine, Faculty of Medicine Ramathibodi Hospital, Mahidol University, 270 Rama VI Road, Bangkok \\ 10400, Thailand \\ ${ }^{2}$ Pharmacy Department, Ramathibodi Hospital, Mahidol University, 270 Rama VI Road, Bangkok 10400, Thailand \\ ${ }^{3}$ Department of Medical Sciences, Ministry of Public Health, Foreign Affairs Section, $3^{\text {rd }}$ Floor, Building 1, Nonthaburi \\ 11000, Thailand \\ ${ }^{4}$ Department of Pathology, Faculty of Medicine Ramathibodi Hospital, Mahidol University, 270 Rama VI Road, \\ Bangkok 10400, Thailand
}

\begin{abstract}
Background: Rash is the most common adverse effect associated with nevirapine (NVP). We aimed to develop a model and risk score for predicting NVP-associated rash among HIV-infected patients with low CD4 cell counts.

Methods: Cross-sectional study was conducted and 383 HIV-infected patients consecutively enrolled in the study.

Results: Of 222 patients in the training set, 116 (52.2\%) were males and median (IQR) age was 35.2 (31.1-42.0) years. Median (IQR) CD4 cell count was $104(35-225)$ cells $/ \mathrm{mm}^{3}$. Of these, 72 and 150 patients were in "rash" and "no rash" group, respectively. Four factors were independently associated with rash: a history of drug allergy (odds ratio (OR) 4.01, $95 \%$ confidence interval $(\mathrm{CI}), 1.75-9.20, P=0.001$ ), body weight $<55 \mathrm{~kg}$. (OR 2.02, 95\% CI, 1.09-3.76, $\mathrm{p}=0.026$ ), not receiving slow dose escalation (OR 2.00, 95\% CI, 1.06-3.77, $\mathrm{p}=0.032)$, and no concomitant drug(s) $(\mathrm{OR} 2.48,95 \% \mathrm{CI}$, $1.32-4.64, \mathrm{p}=0.005)$. Receiver-operator characteristic analysis yielded area under the curve of $71 \%$ and the goodness-offit statistics was $6.48(\mathrm{p}=0.840)$. The variables were given scores of $14,7,7$ and 9 , respectively. A cutoff $>21$ points defined the high risk individuals which yielded specificity and positive predictive value of $99 \%$ and $69 \%$, respectively, with OR of $3.96(95 \% \mathrm{CI}, 1.79-8.86, \mathrm{p}=0.001)$.

Conclusions: A model and risk score for predicting NVP-associated rash performed well in this study population. It might be useful for predicting the risk of rash before NVP initiation among HIV-infected patients with low CD4 cell counts.
\end{abstract}

Keywords: HIV, model, nevirapine, prediction, rash, risk factor.

\section{INTRODUCTION}

Some factors including patients'co-morbidity, adherence, convenience, adverse drug effects, drug-drug interactions, and pregnancy potential have to be considered when selecting an initial regimen of antiretroviral therapy (ART) for HIV-infected patients [1]. In addition, one should consider gender and pretreatment CD4 cell counts in case of nevirapine (NVP) initiation [1]. Use of non-nucleoside

\footnotetext{
*Address correspondence to this author at the Department of Medicine, Faculty of Medicine Ramathibodi Hospital, 270 Rama VI Rd., Bangkok 10400, Thailand; Tel: 662201 1922; Fax: 662201 2232;

E-mail: rasal@mahidol.ac.th
}

${ }^{\S}$ Meeting: Some parts of this study were presented as a poster at the $48^{\text {th }}$ Annual Interscience Conference on Antimicrobial Agents and Chemotherapy (ICAAC)/ Infectious Diseases Society of America (IDSA) the $46^{\text {th }}$ Annual Meeting, October 25-28, 2008, Washington D.C. [abstract H-2294]. reverse transcriptase inhibitor-based regimens as initial therapy can preserve protease inhibitors (PIs) for later use, thus reducing or delaying patient exposure to some of the adverse effects of PIs [1].

NVP is widely used as a component of the first-line ART in resource-limited countries because of the availability of generic drug at low cost and fixed-dose combination tablets. Nevertheless, NVP is not recommended to use in adult females with CD4 $>250$ cells $/ \mathrm{mm}^{3}$ and males with CD4 $>400$ cells $/ \mathrm{mm}^{3}$ due to a high rate of hepatotoxicity [1]. Furthermore, the development of rash in HIV-infected individuals receiving NVP is the most common adverse effect especially during the first few weeks of therapy, with frequencies ranging from 9 to $32 \%$ [2-8]. Rare but serious hypersensitivity reactions, Stevens-Johnson Syndrome and toxic epidermal necrolysis, had been reported $[5,9,10]$. Risk factors for NVP-associated rash were female gender including pregnant women [11-14], lower body weight [15], initiation of NVP at high CD4 cell counts $[11,12,15,16]$, 
pretreated with antiretroviral drugs less than 12 months [17], higher plasma NVP level [17], and genetic (human leukocyte antigen) $[18,19]$. However, some factors may not be applicable to patients who were initiated NVP at low CD4 cell counts in resource-limited settings. In addition, some risk factors differ among study population and from patients to patients.

NVP-associated rash can be minimized by escalating the initial dose of NVP or lead-in prescription [13, 20]. Despite this intervention, rash continues to be the leading cause of NVP discontinuation [21, 22]. Use of antihistamines and/or glucocorticoids cannot prevent this adverse effect [13, 23, 24]. In some situations, NVP-based regimen is the only regimen that can be used, but one cannot predict the probability or risk of NVP-associated rash before NVP initiation for each particular individuals. We aimed to develop a model and risk score for predicting NVPassociated rash among HIV-infected patients who were initiated NVP at low CD4 cell counts in resource-limited settings.

\section{METHODS}

A cross-sectional study of HIV-infected patients, who attended the Infectious Diseases Clinic, Ramathibodi Hospital (a 1,000-bed University Hospital), Mahidol University, Bangkok, Thailand was conducted. Consecutive enrollment of patients had been done between March 2006 and August 2007. Inclusion criteria were adult ( $>15$ years old) HIV-infected patients and received a generic fixed-dose combination of stavudine, lamivudine, and NVP (GPO$\mathrm{VIR}^{\circledR}$ ). Each eligible patient was followed, at least, from initiating NVP until six weeks after NVP initiation. Rash associated with NVP was diagnosed by physicians. If patients received concomitant drugs, which also had a high possibility to cause rash and the diagnosis of causative drug was equivocal, these patients were not included in the study. Concomitant drugs defined as any drugs apart from antiretroviral drugs of the current regimen, i.e., cotrimoxazole, fluconazole, anti-tuberculosis drugs, antihypertensive drugs, and lipid-lowering agents.

To obtain an unbiased estimate of sample population, $60 \%$ of study population was randomly selected from a total study population as a training set. The rest was used as a validation set. Demographic and clinical data were retrieved and reviewed retrospectively as previously described [15]. The study was approved by the Institutional Review Board.

\section{Statistical Analysis}

Continuous variables with normal distribution are presented as mean and standard deviation (SD) and those with non-normal distribution are shown as median and interquartile range (IQR). Continuous variables were compared between groups using independent $t$-test or MannWhitney $\mathrm{U}$ test. Continuous variables were divided into categories to facilitate risk estimation according to the distribution of the variables as well as clinical significance. Age was categorized into $\leq 35 v s>35$ years old, body weight was categorized into $\leq 55 v s>55 \mathrm{~kg}$., and CD4 cell counts were categorized into $\leq 100 v s>100$ cells $/ \mathrm{mm}^{3}$. Categorical variables are shown as frequency and percentage. Chi-square test or Fisher's exact test was used for analysis where appropriate for categorical ones.

Simple logistic regression analysis was used to determine the association between risk factors and outcome (presence of NVP-associated rash). Variables that presented $p<0.25$, were considered in a multiple logistic regression model after assessment of multicollinearity of variance inflation factors. We also considered two more variables, gender [11, 25-27] and previous AIDS-defining illness [15], that had been reported as the risk factors for NVP-associated rash in the model. Variables were selected into a multiple logistic regression model with backward selection. The model was reduced by excluding variables with $p>0.05$ in order to retain a simpler diagnostic model containing only the strongest determinants of NVP-associated skin rash. Thus, variables that attained a level of significance $(\mathrm{p}<0.05)$ were retained in the model [28]. We then compared the final model from backward selection with the initial model by using a likelihood ratio test and Akaike's information criterion. A weighted risk score was constructed using logistic regression coefficients. These coefficients were converted into scores by multiplying by ten and rounded off to the nearest whole number that were added up to obtain an aggregated score [29].

Two performance indexes were used to estimate the discrimination and calibration of the predictive model. The discrimination was evaluated using the area under the receiver-operator characteristic (ROC) curve [30] and the calibration was measured using the Pearson's goodness-of-fit test. An area under the ROC curve of 1.0 is ideal whereas it is $<0.5$ indicates no diagnostic accuracy. In general, the area under the ROC curve $>0.7$ indicates a useful test [31]. The Pearson's goodness-of-fit test has a p-value of $>0.05$ is considered being the good calibration model. The optimum cut-off point for the score was determined by sensitivity, specificity, positive predictive value, and negative predictive value. A p-value $<0.05$ was considered statistically significance. All statistical analyses were performed using Stata statistical software version 10.0 (Stata Statistical Software: Release 10.0, Stata Corporation, College Station, TX, 2007).

\section{RESULTS}

Initially, 383 patients were included in the study but 13 (3.4\%) patients were excluded because of missing clinical data of interests. The derivation group from random sampling was further analyzed. A total of 222 patients with a median (IQR) age of $35.2(31.1-42.0)$ years were in a training set. Of these, $116(52.2 \%)$ were males and median (IQR) body weight was $54.0(48.0-63.0) \mathrm{kg}$. The most common route of HIV acquisition was heterosexual (98\%). Thirty-two (14.4\%) patients had a history of drug allergy and 134 (60.4\%) patients receiving concomitant drug(s). Median (IQR) CD4 cell count at time of NVP initiation was 104 (35225) cells $/ \mathrm{mm}^{3}$. Prior to NVP initiation, $154(69.4 \%)$ patients were naive to ART. Slow dose escalation of NVP was prescribed in $151(68.0 \%)$ patients. 
Table 1. Baseline Demographics and Clinical Characteristics of Patients by Nevirapine-Associated Rash Status

\begin{tabular}{|c|c|c|c|c|}
\hline Variables & $\begin{array}{c}\text { Total } \\
(\mathrm{n}=\mathbf{2 2 2})\end{array}$ & $\begin{array}{c}\text { Rash } \\
(n=72)\end{array}$ & $\begin{array}{l}\text { No Rash } \\
(\mathrm{n}=150)\end{array}$ & $P$-Value \\
\hline Age, median (IQR), years & $\begin{array}{c}35.2 \\
(31.1-42.0)\end{array}$ & $\begin{array}{c}35.0 \\
(31.2-40.6)\end{array}$ & $\begin{array}{c}35.2 \\
(30.9-42.2)\end{array}$ & 0.918 \\
\hline Male, $n(\%)$ & $\begin{array}{c}116 \\
(52.2)\end{array}$ & $\begin{array}{c}38 \\
(52.8)\end{array}$ & $\begin{array}{c}68 \\
(45.3)\end{array}$ & 0.318 \\
\hline Body weight, median (IQR), kg. & $\begin{array}{c}54.0 \\
(48.0-63.0)\end{array}$ & $\begin{array}{c}53.0 \\
(48.0-59.0)\end{array}$ & $\begin{array}{c}55.0 \\
(48.0-65.0)\end{array}$ & 0.918 \\
\hline HIV transmission by heterosexual, $\mathrm{n}(\%)$ & $\begin{array}{c}217 \\
(97.8)\end{array}$ & $\begin{array}{c}69 \\
(95.8)\end{array}$ & $\begin{array}{c}148 \\
(98.7)\end{array}$ & 0.227 \\
\hline History of AIDS-defining illness, n (\%) & $\begin{array}{c}107 \\
(48.2)\end{array}$ & $\begin{array}{c}31 \\
(43.1)\end{array}$ & $\begin{array}{c}76 \\
(50.7)\end{array}$ & 0.317 \\
\hline Concomitant other underlying illness(s), $\mathrm{n}(\%)$ & $\begin{array}{c}32 \\
(14.4)\end{array}$ & $\begin{array}{c}13 \\
(18.1)\end{array}$ & $\begin{array}{c}19 \\
(12.7)\end{array}$ & 0.310 \\
\hline History of drug allergy, $\mathrm{n}(\%)$ & $\begin{array}{c}32 \\
(14.4)\end{array}$ & $\begin{array}{c}18 \\
(25.0)\end{array}$ & $\begin{array}{c}14 \\
(9.3)\end{array}$ & 0.004 \\
\hline Receiving concomitant drug(s), n (\%) & $\begin{array}{c}134 \\
(60.4)\end{array}$ & $\begin{array}{c}34 \\
(47.2)\end{array}$ & $\begin{array}{c}100 \\
(66.7)\end{array}$ & 0.008 \\
\hline Naive to antiretroviral therapy, $\mathrm{n}(\%)$ & $\begin{array}{c}154 \\
(69.4)\end{array}$ & $\begin{array}{c}41 \\
(56.9)\end{array}$ & $\begin{array}{c}113 \\
(75.3)\end{array}$ & 0.008 \\
\hline Switching from efavirenz, $\mathrm{n}(\%)$ & $\begin{array}{c}44 \\
(29.8)\end{array}$ & $\begin{array}{c}19 \\
(26.4)\end{array}$ & $\begin{array}{c}25 \\
(16.7)\end{array}$ & 0.106 \\
\hline Receiving slow dose escalation of NVP, n (\%) & $\begin{array}{c}151 \\
(68.0)\end{array}$ & $\begin{array}{c}40 \\
(55.6)\end{array}$ & $\begin{array}{c}111 \\
(74.0)\end{array}$ & 0.009 \\
\hline CD4 cell count at time of NVP initiation, median (IQR), cells $/ \mathrm{mm}^{3}$ & $\begin{array}{c}104 \\
(35-225)\end{array}$ & $\begin{array}{c}191 \\
(61-290)\end{array}$ & $\begin{array}{c}72 \\
(23-200)\end{array}$ & 0.001 \\
\hline
\end{tabular}

Abbreviation: IQR, interquartile range, NVP, nevirapine.

There were 72 patients in "rash" group and 150 patients in "no rash" group. Of 72 patients, 34,35 , and 3 patients developed grade 2, 3, and 4 of rash according to Division of AIDS table for grading the severity of adult and pediatric adverse events [32]. In rash group, a higher proportion of male gender $(52.8 \%$ vs $45.3 \%, \mathrm{p}=0.318)$, patients with a history of drug allergy $(25.0 \%$ vs $9.3 \%, \mathrm{p}=0.004)$, and switching from efavirenz (EFV) $(26.4 \%$ vs $16.7 \%$, p = $0.106)$ were found. In contrast, patients without rash had a higher proportion of receiving concomitant drug(s) $(66.7 \%$ vs $47.2 \%, \mathrm{p}=0.008)$, naive to ART $(75.3 \%$ vs $56.9 \%, \mathrm{p}=$ $0.008)$, and prescribed slow dose escalation of NVP $(74.0 \%$ vs 55.6\%, $\mathrm{p}=0.009)$. Median CD4 cell count at the time of NVP initiation was higher among patients in rash group (191 vs 72 cells $\left./ \mathrm{mm}^{3}, \mathrm{p}=0.001\right)$. Baseline demographics and clinical characteristics of patients by NVP-associated rash status are shown in Table $\mathbf{1}$.

We found five factors related to NVP-associated rash by simple logistic regression. These were a history of drug allergy (odds ratio (OR) 3.24, 95\% confidence interval (CI), 1.50-6.97, $\mathrm{p}=0.003$ ), no concomitant $\operatorname{drug}(\mathrm{s})$ (OR 2.24, 95\% CI, 1.26-3.97, p = 0.006), naive to ART (OR 2.31, 95\% $\mathrm{CI}, 1.27-4.19, \mathrm{p}=0.006$ ), not receiving slow dose escalation of NVP (OR 2.28, 95\% CI, 1.26-4.11, p = 0.006), and CD4 cell counts at time of NVP initiation $>100$ cells $/ \mathrm{mm}^{3}$ (OR $2.69,95 \%$ CI, 1.49-4.83, $\mathrm{p}=0.001)($ Table 2$)$.
In multiple logistic regression, the independent predictor variables of NVP-associated rash are shown in Table 3. These were a history of drug allergy (OR 4.01, 95\% CI, $1.75-9.20, \mathrm{p}=0.001)$, no concomitant $\operatorname{drug}(\mathrm{s})(\mathrm{OR} 2.48$, $95 \%$ CI, 1.32-4.64, $\mathrm{p}=0.005$ ), body weight $\leq 55 \mathrm{~kg}$. (OR $2.02,95 \% \mathrm{CI}, 1.09-3.76, \mathrm{p}=0.026)$, and not receiving slow dose escalation of NVP (OR 2.00, 95\% CI, 1.06-3.77, p = 0.032 ). A ROC curve was plotted to determine the ability of the model for correctly predicting the NVP-associated rash. The area under the ROC curve was $71 \%$, indicating good model discriminatory power between individuals with and without rash (Fig. 1). The Pearson's goodness-of-fit statistic value was $6.48(\mathrm{p}=0.840)$, indicating excellent model calibration for the observed versus the predicted outcome. When the model was applied to the remaining 148 patients who comprised the validation set, the model still showed good calibration (Pearson's goodness-of-fit statistic of 15.61, $\mathrm{p}=0.156$ ) and fair discrimination (area under the ROC curve of $65 \%)$.

A numerical score was formulated by using logistic regression coefficients for risk score calculation. A history of drug allergy, body weight $\leq 55 \mathrm{~kg}$., not receiving slow dose escalation of NVP, and no concomitant drug(s) were assigned scores of 14, 9, 7 and 7, respectively. The equation used for the NVP-associated rash risk score calculation for each patient was: NVP-associated rash risk score $=14$ 
Table 2. Simple Logistic Regression Analysis of the Variables Related to Nevirapine-associated Rash

\begin{tabular}{|c|c|c|c|}
\hline Variables & Odds Ratio & $95 \% \mathrm{CI}$ & $P$-Value \\
\hline Male gender & 1.35 & $0.77-2.37$ & 0.299 \\
\hline Body weight $(\leq 55 v s>55 \mathrm{~kg}$.) & 1.72 & $0.97-3.07$ & 0.065 \\
\hline HIV transmission by heterosexual & 0.31 & $0.05-1.90$ & 0.206 \\
\hline Concomitant other underlying illness(s) & 1.52 & $0.70-3.28$ & 0.287 \\
\hline History of drug allergy & 3.24 & $1.50-6.97$ & 0.003 \\
\hline No concomitant drug(s) & 2.24 & $1.26-3.97$ & 0.006 \\
\hline Naive to antiretroviral therapy & 2.31 & $1.27-4.19$ & 0.006 \\
\hline
\end{tabular}

Abbreviation: $\mathrm{CI}$, confidence interval, NVP, nevirapine.

Table 3. Multiple Logistic Regression Analysis of the Variables Related to Nevirapine-Associated Rash

\begin{tabular}{|c|c|c|c|c|c|}
\hline Variables & $\begin{array}{c}\text { Estimated Regression Coefficient } \\
\text { (Standard Error) }\end{array}$ & Odds Ratio & $95 \% \mathrm{CI}$ & $P$-Value & Score (Points) \\
\hline History of drug allergy & $1.38(0.42)$ & 4.01 & $1.75-9.20$ & 0.001 & 14 \\
\hline No concomitant drug(s) & $0.91(0.32)$ & 2.48 & $1.32-4.64$ & 0.005 & 9 \\
\hline Body weight ( $\leq 55 v s>55 \mathrm{~kg}$.) & $0.70(0.32)$ & 2.02 & $1.09-3.76$ & 0.026 & 7 \\
\hline Not receiving slow dose escalation of NVP & $0.69(0.32)$ & 2.00 & $1.06-3.77$ & 0.032 & 7 \\
\hline
\end{tabular}

Abbreviation: CI, confidence interval, NVP, nevirapine.

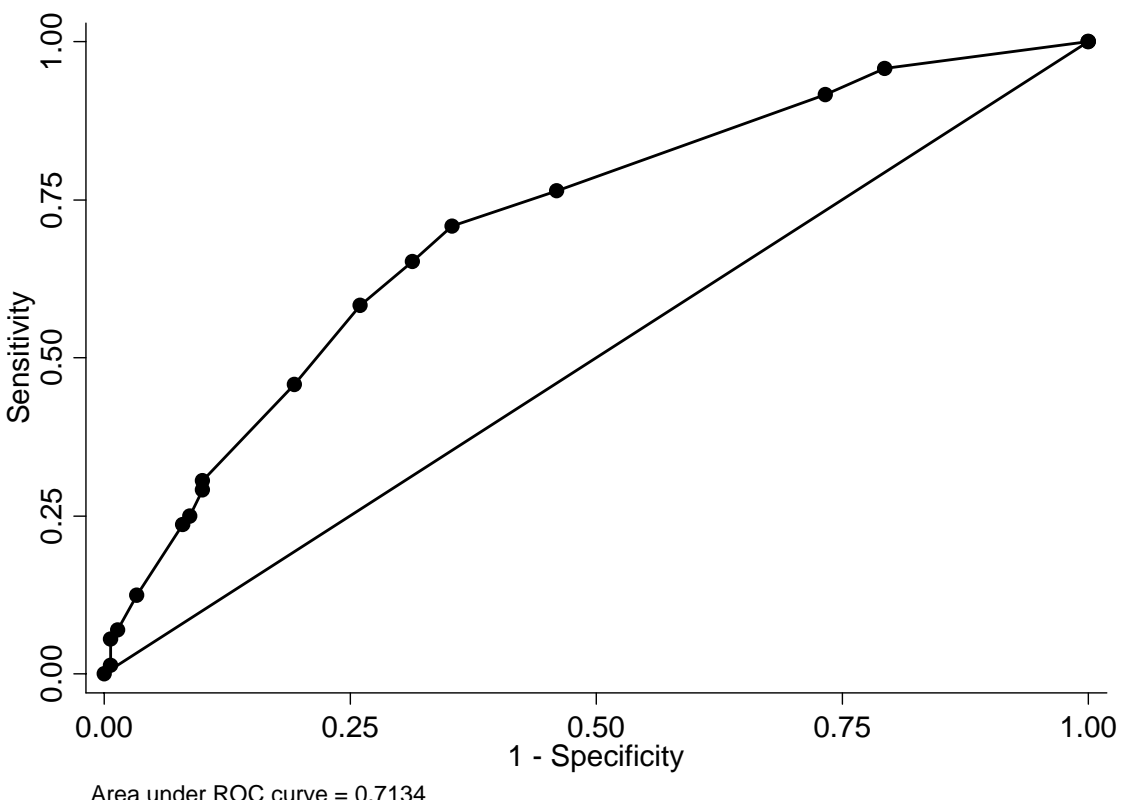

Fig. (1). Receiver-operator characteristic (ROC) plot of the model composed of a history of drug allergy, body weight $\leq 55 \mathrm{~kg}$., not receiving slow dose escalation, and no concomitant $\operatorname{drug}(\mathrm{s})$. 
(a history of drug allergy) +9 (no concomitant drug(s)) +7 (body weight $\leq 55 \mathrm{~kg}$.) +7 (not receiving slow dose escalation of NVP). For each of the variables, a value of " 1 " was assigned if the variable was present or " 0 " of it was absent. The median (IQR) risk score of patients in rash group and no rash group was 16 (9-22) points and 7 (7-16) points, respectively $(p<0.001)$. The distribution of risk score among HIV-infected patients with and without NVP-associated rash is shown in Table 4. If the total score was $\geq 21$ points, the individual was defined as high risk for NVP-associated rash, otherwise was low risk. There were 22 of $72(30.6 \%)$ patients in rash group and 15 of $150(10.0 \%)$ had a risk score above the cutoff who were defined as high risk individuals $(\mathrm{p}<0.001)$. A cutoff at 21 points yielded specificity and positive predictive value of $99 \%$ and $69 \%$, respectively. In addition, patients who had a risk score $\geq 21$ points had odds of NVP-associated rash 3.96 times higher than those who had a score of $<21$ points (OR 3.96, 95\% CI, 1.79-8.86, $\mathrm{p}=$ $0.001)$.

Table 4. Distribution of HIV-Infected Patients with and without Nevirapine-Associated Rash in Relation to the Risk Score Obtained

\begin{tabular}{|c|c|c|c|}
\hline $\begin{array}{c}\text { Risk } \\
\text { Score }\end{array}$ & $\begin{array}{c}\text { Rash } \\
\mathbf{n}(\%)\end{array}$ & $\begin{array}{c}\text { No Rash } \\
\mathbf{n}(\mathbf{\%})\end{array}$ & $\begin{array}{c}\text { Total } \\
\mathbf{n}(\%)\end{array}$ \\
\hline \hline 0 & 3 & 31 & 34 \\
& $(4.2)$ & $(20.7)$ & $(15.3)$ \\
\hline 7 & 14 & 50 & 64 \\
& $(19.4)$ & $(33.3)$ & $(28.8)$ \\
\hline 9 & 4 & 16 & 20 \\
& $(5.6)$ & $(10.8)$ & $(9.0)$ \\
\hline 14 & 9 & 14 & 23 \\
& $(12.4)$ & $(9.4)$ & $(10.4)$ \\
\hline 16 & 20 & 24 & 44 \\
& $(27.8)$ & $(16.0)$ & $(19.8)$ \\
\hline 21 & 4 & 2 & 6 \\
& $(5.6)$ & $(1.3)$ & $(2.7)$ \\
\hline 23 & 9 & 8 & 17 \\
& $(12.4)$ & $(5.3)$ & $(7.7)$ \\
\hline 28 & 4 & 3 & 7 \\
& $(5.6)$ & $(2.0)$ & $(3.2)$ \\
\hline 30 & 4 & 1 & 5 \\
& $(5.6)$ & $(0.7)$ & $(2.2)$ \\
\hline \multirow{2}{*}{37} & 1 & 1 & 2 \\
& $(1.4)$ & $(0.7)$ & $(0.9)$ \\
\hline \multirow{2}{*}{$30 t a l$} & $(100.0)$ & $150(100.0)$ & $(100.0)$ \\
\hline
\end{tabular}

The equation used for the NVP-associated rash risk score calculation: NVP-associated rash risk score $=14$ (a history of drug allergy) +9 (no concomitant drug $(\mathrm{s}))+7$ (body weight $\leq 55 \mathrm{~kg}$.) +7 (not receiving slow dose escalation of NVP)

\section{DISCUSSION}

The present study was the first one, which was conducted to develop prediction model and risk score for NVPassociated rash in advanced HIV-infected patients. Approximately half of the patients had a history of AIDSdefining illness and the median CD4 cell count at time of
NVP initiation was approximately 100 cells $/ \mathrm{mm}^{3}$. This study well represented the target population in resourceconstrained settings. According to clinical characteristics between the two groups, there was a lower proportion of patients prescribed slow dose escalation of NVP in rash group (55.6\% vs $74.0 \%, \mathrm{p}=0.009)$. Furthermore, patients in rash group also had a higher proportion of switching EFV to NVP but there was no statistically significant difference (26.4\% vs 16.7\%). These two factors might be correlated because when changing from EFV to NVP, full dose of NVP should be started. Slow dose escalation of NVP after EFV treatment can lead to lower therapeutic plasma drug levels because EFV induces the metabolism of co-administered drugs through the induction of CYP $3 \mathrm{~A} 4$ as it has been shown in a pharmacokinetic study [33]. However, multicollinearity was not found after variance inflation factors assessment of these 2 variables.

We found four independent factors associated with rash, namely a history of drug allergy, no concomitant drug(s), body weight $\leq 55 \mathrm{~kg}$., and not receiving slow dose escalation. These factors had been reported as related factors for NVPassociated rash in the previous studies [13, 15, 17, 20, 34]. Patients who had a history of drug allergy had been reported as a risk factor of NVP-associated rash among Thai HIVinfected patients, especially those who had a history of sulfamethoxazole allergy [34]. Patients who took concomitant drug(s), which mostly (88.8\%) were fluconazole and co-trimoxazole (data not shown), might have lower NVP plasma level than normal value due to enzyme induction of, especially, fluconazole [35]. The probable higher plasma NVP level might explain why patients who did not take concomitant $\operatorname{drug}(\mathrm{s})$ had a higher risk of rash. In addition, patients who were not taking other medications had a lower proportion of previous AIDSdefining illness $(31.8 \%$ vs $59.0 \%, \mathrm{p}<0.001)$ (data not shown) which reflected in higher CD4 cell counts. Both AIDSdefining illness and high CD4 cell counts at the time of NVP initiation were found to be associated with NVP-associated rash in the previous study [15]. Patients with higher body weight might have lower NVP plasma concentration and linked to lower risk of NVP-associated rash [36]. Clearly, slow dose escalation of NVP minimizes the risk for toxicity $[13,20]$.

No association between gender and CD4 cell count and risk of NVP-associated rash were observed in the present study even though these two factors were consistently reported in some studies [11-16]. We did not find any association between gender and risk of rash in our previous study using the same cohort [15]. CD4 cell count was associated with rash in simple logistic regression analysis of our present data, but it was not a risk factor after control of other variables.

Despite the fact that NVP-based regimen is the most commonly use in many countries, there was no model developed for health care providers to guide and/or predict NVP-associated rash before prescribing NVP especially in resource-limited settings. These factors from our model could be combined to create a risk index and risk score for 
predicting NVP-associated rash. Identifying risk factors associated with rash is relevant when health care provider need to prescribe NVP to HIV-infected patients. Counseling and informing patients regarding risk of rash associated with NVP is crucial for prevention the consequence from NVP adverse effects including adherence improvement [37]. This particular model was developed by selecting the significant factors from logistic regression analysis including factors that had an a priori biological and/or clinical rationale. A weighted risk score was constructed using logistic regression coefficients. Selecting the final model based on the statistical criteria for good discrimination and calibration of the predictive model. This model considered to be a good candidate, despite the decreased area under the ROC curve of the validation set. The model is "over-optimism" [38], i.e. the area under the curve will almost always be worse in the validation set than training set. The risk score is also developed for predicting risk of NVP-associated rash. This relative simple risk score, with the cutoff $\geq 21$ points, showed a high specificity and positive predictive value. If patients had a risk score of $\geq 21$, either EFV or PIs should be considered as an alternative in the resource limitation because of a high risk of NVP-associated rash. However, physicians should discuss risk and benefit, including close follow-up patients. High risk of unsuccessful switching from NVP to EFV was found in patients who had a history of drug allergy apart from NVP and had CD4 cell counts less than 100 cells $/ \mathrm{mm}^{3}$ [39]. In the resource-limited settings, where both EFV and PIs are not available, or patients cannot tolerate both EFV and PIs, NVP might be used with caution, including slow dose escalation, closed monitoring of both clinical and liver function tests after assessing risk and benefit.

The present study had some limitations. First, there were some missing data, but it was a small proportion, and we excluded these patients from the analysis. However, we believed that model-wise deletion analysis for defining the prediction model was not bias. Second, we included only clinical characteristics and CD4 cell count in the model because these variables can apply to most of HIV-infected patients in resource-limited settings. Some laboratory variables may improve the discrimination power if they were added in the model. Third, we had to categorize continuous variables into category ones for the model building and the pre-defined cut point was arbitrary decision. This might loose information and significant association between variables and outcome. Last, this study was conducted among Thai patients, which tended to have a relative higher prevalence of NVP-associated rash. High prevalence of NVP rash in Thai patients might be explained by genetic factor. Our group recently found the strong association of $H L A$ $B * 3505$ allele among Thai HIV-infected patients who developed NVP-associated rash [40]. Thus, generalization of these findings to other races should be considered cautiously.

In conclusion, a model and risk score for predicting NVP-associated rash among HIV-infected performed well in this particular study population. It might be useful for predicting the risk of rash before NVP initiation among HIVinfected patients with low CD4 cell counts especially in resource-limited setting where NVP is widely used. It is also important to monitor NVP-associated rash among HIVinfected patients with a history of drug allergy, low body weight $(\leq 55 \mathrm{~kg})$, not receiving slow dose escalation, and concomitant drug(s). In addition, further validation of this model and risk score in other populations is required.

\section{AUTHORS' CONTRIBUTIONS}

SK carried out designed the study, developed case record form, recruited study participants, collected data, preformed statistical analysis, and drafted the manuscript. SS carried out participant recruitment and helped to draft the manuscript. KM carried out participant recruitment and helped to draft the manuscript. SW carried out participant recruitment. BS carried out participant recruitment. AC carried out study coordination. SM carried out helped to draft the manuscript. WC carried out study coordination. All authors read and approved the final manuscript.

\section{ACKNOWLEDGEMENTS}

The authors would like to thank all the attending staffs and physicians in the Division of Infectious Diseases, Department of Medicine for taking care of patients and for their supports. This work was supported by grant from Thailand Center of Excellence for Life Sciences (TCELS).

\section{REFERENCES}

[1] Guidelines for the use of antiretroviral agents in HIV-1-Infected adults and adolescents. U. S. Department of Health and Human Services (DHHS). November 3, 2008. http://aidsinfo.nih.gov/ contentfiles/AdultandAdolescentGL.pdf (accessed December 1, 2008).

[2] D'Aquila RT, Hughes MD, Johnson VA, et al. Nevirapine, zidovudine, and didanosine compared with zidovudine and didanosine in patients with HIV-1 infection. A randomized, doubleblind, placebo-controlled trial. National Institute of Allergy and Infectious Diseases AIDS Clinical Trials Group Protocol 241 Investigators. Ann Intern Med 1996, 124: 1019-30.

[3] Viramune package insert. Ridgefield, CT: Boehringer Ingelheim Pharmaceuticals, Inc, January 2004.

[4] Carr A, Cooper DA. Adverse effects of antiretroviral therapy. Lancet 2000, 356: 1423-30.

[5] Pollard RB, Robinson P, Dransfield K. Safety profile of nevirapine, a nonnucleoside reverse transcriptase inhibitor for the treatment of human immunodeficiency virus infection. Clin Ther 1998, 20: 1071-92.

[6] Montessori V, Press N, Harris M, Akagi L, Montaner JS. Adverse effects of antiretroviral therapy for HIV infection. CMAJ 2004, 170: $229-38$

[7] Carr A, Vella S, de Jong MD, et al. A controlled trial of nevirapine plus zidovudine versus zidovudine alone in p24 antigenaemic HIVinfected patients. The Dutch-Italian-Australian Nevirapine Study Group. AIDS 1996, 10: 635-41.

[8] Kiertiburanakul S, Khongnorasat S, Rattanasiri S, Sungkanuparph S. Efficacy of a generic fixed-dose combination of stavudine, lamivudine and nevirapine (GPO-VIR) in Thai HIV-infected patients. J Med Assoc Thai 2007, 90: 237-43.

[9] Metry DW, Lahart CJ, Farmer KL, Hebert AA. Stevens-Johnson syndrome caused by the antiretroviral drug nevirapine. J Am Acad Dermatol 2001, 44 (Suppl 3): 354-7.

[10] Namayanja GK, Nankya JM, Byamugisha JK, et al. Stevens Johnson syndrome due to nevirapine. Afr Health Sci 2005, 5: 33840.

[11] Ananworanich J, Moor Z, Siangphoe U, et al. Incidence and risk factors for rash in Thai patients randomized to regimens with nevirapine, efavirenz or both drugs. AIDS 2005, 19: 185-92.

[12] van Leth F, Andrews S, Grinsztejn B, et al. The effect of baseline CD4 cell count and HIV-1 viral load on the efficacy and safety of 
nevirapine or efavirenz-based first-line HAART. AIDS 2005, 19: 463-71.

[13] Antinori A, Baldini F, Girardi E, et al. Female sex and the use of anti-allergic agents increase the risk of developing cutaneous rash associated with nevirapine therapy. AIDS 2001; 15: 1579-81.

[14] Kondo W, Carraro EA, Prandel E, et al. Nevirapine-induced side effects in pregnant women: experience of a Brazilian university hospital. Braz J Infect Dis 2007; 11: 544-8.

[15] Kiertiburanakul S, Sungkanuparph S, Charoenyingwattana A, Mahasirimongkol S, Sura T, Chantratita W. Risk factors for nevirapine-associated rash among HIV-infected patients with low CD4 cell counts in resource-limited settings. Curr HIV Res 2008; 6: 65-9.

[16] Manosuthi W, Sungkanuparph S, Tansuphaswadikul S, et al. Incidence and risk factors of nevirapine-associated skin rashes among HIV-infected patients with CD4 cell counts $<250$ cells/microL. Int J STD AIDS 2007; 18: 782-6.

[17] de Maat MM, ter Heine R, Mulder JW, et al. Incidence and risk factors for nevirapine-associated rash. Eur J Clin Pharmacol 2003; 59: 457-62.

[18] Martin AM, Nolan D, James I, et al. Predisposition to nevirapine hypersensitivity associated with HLA-DRB $1 * 0101$ and abrogated by low CD4 T-cell counts. AIDS 2005, 19: 97-9.

[19] Vitezica ZG, Milpied B, Lonjou C, et al. HLA-DRB1*01 associated with cutaneous hypersensitivity induced by nevirapine and efavirenz. AIDS 2008, 22: 540-1.

[20] Barreiro P, Soriano V, Casas E, et al. Prevention of nevirapineassociated exanthema using slow dose escalation and/or corticosteroids. AIDS 2000, 14: 2153-7.

[21] Anton P, Soriano V, Jimenez-Nacher I, et al. Incidence of rash and discontinuation of nevirapine using two different escalating initial doses. AIDS 1999, 13: 524-5.

[22] Zhou J, Phanupak P, Kiertiburanakul S, Ditangco R, Kamarulzaman A, Pujary S. TREAT Asia HIV Observational Database: Highly active antiretroviral treatment containing efavirenz or nevirapine and related toxicity in the TREAT Asia HIV Observational Database. J Acquir Immune Defic Syndr 2006, 43: 501-3.

[23] Knobel H, Miro JM, Domingo P, et al. Failure of a short-term prednisone regimen to prevent nevirapine-associated rash: a double-blind placebo-controlled trial: the GESIDA 09/99 study. J Acquir Immune Defic Syndr 2001, 28: 14-8.

[24] Knobel H, Miro JM, Mahillo B, et al. Failure of cetirizine to prevent nevirapine-associated rash: a double-blind placebocontrolled trial for the GESIDA 26/01 Study. J Acquir Immune Defic Syndr 2004, 37: 1276-81.

[25] Clark R. Sex differences in antiretroviral therapy-associated intolerance and adverse events. Drug Saf 2005, 28: 1075-83.

[26] Montaner JS, Cahn P, Zala C, et al. Randomized, controlled study of the effects of a short course of prednisone on the incidence of rash associated with nevirapine in patients infected with HIV-1. J Acquir Immune Defic Syndr 2003 33: 41-6.

[27] Bersoff-Matcha SJ, Miller WC, Aberg JA, et al. Sex differences in nevirapine rash. Clin Infect Dis 2001, 32: 124-9.

[28] Hosmer DW, Lemeshow S. Applied logistic regression. 2nd ed. New York: John Wiley \& Sons Inc 2000.

[29] Moons KG, Harrell FE, Steyerberg EW. Should scoring rules be based on odds ratios or regression coefficients? J Clin Epidemiol 2002, 55: 1054-5.

[30] Hanley JA, McNeil BJ. The meaning and use of the area under a receiver operating characteristic (ROC) curve. Radiology 1982, 143: 29-36.

[31] Rosenberg AL. Recent innovations in intensive care unit riskprediction models. Curr Opin Crit Care 2002, 8: 321-30.

[32] Division of AIDS table for grading the severity of adult and pediatric adverse events. Public date: December, 2004. Available from URL http://www3.niaid.nih.gov/research/resources/DAIDSC linRsrch/PDF/Safety/DAIDSAEGradingTable.pdf.

[33] Winston A, Pozniak A, Smith N, et al. Dose escalation or immediate full dose when switching from efavirenz to nevirapinebased highly active antiretroviral therapy in HIV-1-infected individuals? AIDS 2004, 18: 572-4.

[34] Tansuphaswadikul S, Aung SE, Phonrat B, Kaewkungwal J, Pitisuttithum P, Maek-a-nantawat W. Predisposing factors for nevirapine toxicity among AIDS patients with low baseline CD4 count. Asian Pac J Allergy Immunol 2007, 25: 147-54.

[35] Manosuthi W, Athichathanabadi C, Uttayamakul S, Phoorisri T, Sungkanuparph S. Plasma nevirapine levels, adverse events and efficacy of antiretroviral therapy among HIV-infected patients concurrently receiving nevirapine-based antiretroviral therapy and fluconazole. BMC Infect Dis 2007, 7: 14.

[36] Manosuthi W, Kiertiburanakul S, Chaovavanich A, Sungkanuparph S. Plasma nevirapine levels and 24-week efficacy of a fixed-dose combination of stavudine, lamivudine and nevirapine (GPO-VIR) among Thai HIV-infected patients. J Med Assoc Thai 2007, 90: 244-50.

[37] Fischl MA. Antiretroviral therapy in 1999 for antiretroviral-naive individuals with HIV infection. AIDS 1999, 13: S49-59.

[38] Schumacher M, Holländer N, Sauerbrei W. Resampling and crossvalidation techniques: a tool to reduce bias caused by model building? Stat Med 1997,16: 2813-27.

[39] Kiertiburanakul S, Malathum K, Watcharananan S, Sathapatayavongs B, Sungkanuparph S. Predicting factors for unsuccessful switching from nevirapine to efavirenz in HIV-infected patients who developed nevirapine-associated skin rash. Int J STD AIDS 2009, 20: 176-9.

[40] Chantarangsu S, Mushiroda T, Mahasirimongkol S, et al. HLA-B*3505 allele is a strong predictor for nevirapine-induced skin adverse drug reactions in Thai HIV-infected patients. Pharmacogenet Genomics 2009, 19: 139-46.

This is an open access article licensed under the terms of the Creative Commons Attribution Non-Commercial License (http://creativecommons.org/licenses/by$\mathrm{nc} / 3.0 /$ ) which permits unrestricted, non-commercial use, distribution and reproduction in any medium, provided the work is properly cited. 